\title{
BMJ Open Management of haemothoraces in blunt thoracic trauma: study protocol for a randomised controlled trial
}

\author{
David A Carver, ${ }^{1,2}$ Alexsander K Bressan, ${ }^{1,2}$ Colin Schieman, ${ }^{1,2}$ Sean C Grondin, ${ }^{1,2}$ \\ Andrew W Kirkpatrick, ${ }^{1,2}$ Rohan Lall, ${ }^{1,2}$ Paul B McBeth,, ${ }^{1,2}$ Michael B Dunham, ${ }^{1,2}$ \\ Chad G Ball ${ }^{1,2}$
}

To cite: Carver DA, Bressan AK, Schieman C, et al. Management of haemothoraces in blunt thoracic trauma: study protocol for a randomised controlled trial. BMJ Open 2018:8:e020378. doi:10.1136/ bmjopen-2017-020378

- Prepublication history for this paper is available online. To view these files, please visit the journal online (http://dx.doi. org/10.1136/bmjopen-2017020378 )

Received 31 October 2017 Revised 12 January 2018 Accepted 15 January 2018
Check for updates

${ }^{1}$ Department of Surgery, University of Calgary, Calgary, Alberta, Canada

${ }^{2}$ Foothills Medical Centre, Calgary, Alberta, Canada

Correspondence to

Dr Chad G Ball;

Ball.Chad@gmail.com

\section{ABSTRACT}

Introduction Haemothorax following blunt thoracic trauma is a common source of morbidity and mortality. The optimal management of moderate to large haemothoraces has yet to be defined. Observational data have suggested that expectant management may be an appropriate strategy in stable patients. This study aims to compare the outcomes of patients with haemothoraces following blunt thoracic trauma treated with either chest drainage or expectant management.

Methods and analysis This is a single-centre, dual-arm randomised controlled trial. Patients presenting with a moderate to large sized haemothorax following blunt thoracic trauma will be assessed for eligibility. Eligible patients will then undergo an informed consent process followed by randomisation to either (1) chest drainage (tube thoracostomy) or (2) expectant management. These groups will be compared for the rate of additional thoracic interventions, major thoracic complications, length of stay and mortality.

Ethics and dissemination This study has been approved by the institution's research ethics board and registered with ClinicalTrials.gov. All eligible participants will provide informed consent prior to randomisation. The results of this study may provide guidance in an area where there remains significant variation between clinicians. The results of this study will be published in peer-reviewed journals and presented at national and international conferences. Trial registration number NCT03050502.

\section{INTRODUCTION}

Thoracic injuries are common in patients with blunt polytrauma and are responsible for approximately $25 \%$ of all injury-related mortalities. ${ }^{1}$ Traumatic injuries to the thorax often result in the accumulation of blood within the pleural space (ie, a haemothorax (HTX)). Traditionally, the management of HTXs has included chest tube placement. Although HTXs are effectively managed with tube thoracostomy (TT), this intervention is associated with a number of potentially serious complications including iatrogenic injury, retained HTXs and empyema in up to $22 \%$ of patients. ${ }^{2-5}$

\section{Strengths and limitations of this study}

- First randomised controlled trial designed to clarify the role of chest drainage for blunt traumatic haemothorax.

- The nature of the intervention groups does not allow for blinding.

This is a single-centre study.

Prior to the ubiquitous use of chest CT, diagnosing quantities of blood $<1000 \mathrm{~mL}$ was challenging. With the widespread adoption of CT 'pan-scanning', however, significantly more HTXs are being detected. The clinical significance and optimal treatment of these small to moderate HTXs remain unknown. ${ }^{6}$

The East American Association of Trauma guidelines suggest that all HTXs should be considered for TT drainage. ${ }^{7}$ However, several retrospective studies suggest that many traumatic HTXs can be managed expectantly without TT drainage. ${ }^{8-12}$ A prospective observational study also suggests that small to moderate HTXs (<300cc of blood) can be absorbed without intervention. ${ }^{5}$ Classic studies from the 1960s indicate that much larger quantities of blood can be reabsorbed without intervention as well. ${ }^{1314}$ As a result, the management of HTXs remains a clinical dilemma when the volume of blood is moderate to large and the patient is haemodynamically stable.

This study aims to evaluate the rate of additional thoracic interventions after expectant management as compared with upfront pleural drainage in patients with moderate to large volume haemothoraces secondary to blunt trauma.

\section{METHODS AND ANALYSIS Overview}

The study will be a single-centre, dual-arm, parallel randomised controlled trial. Patients 


\begin{tabular}{|c|c|c|c|c|c|c|c|}
\hline & \multicolumn{7}{|c|}{ STUDY PERIOD } \\
\hline & \multirow{2}{*}{$\begin{array}{l}\text { Enrolment } \\
\text { Within } 24 \mathrm{hrs}\end{array}$} & \multirow{2}{*}{$\begin{array}{c}\text { Allocation } \\
\text { Within } 24 \mathrm{hrs}\end{array}$} & \multicolumn{3}{|c|}{ Post-Admission Day } & \multicolumn{2}{|c|}{$\begin{array}{l}\text { Post-Discharge } \\
\text { Followup }\end{array}$} \\
\hline TIMEPOINT & & & 1 & .. & $D / C$ & 30 days & 90 days \\
\hline \multicolumn{8}{|l|}{ ENROLMENT: } \\
\hline Eligibility screen & $x$ & & & & & & \\
\hline Informed consent & $x$ & & & & & & \\
\hline Randomization & & $x$ & & & & & \\
\hline Allocation & & $x$ & & & & & \\
\hline \multicolumn{8}{|l|}{ INTERVENTIONS: } \\
\hline \multicolumn{8}{|l|}{ Tube Thoracostomy } \\
\hline \multicolumn{8}{|l|}{$\begin{array}{r}\text { Expectant } \\
\text { Management }\end{array}$} \\
\hline \multicolumn{8}{|l|}{ ASSESSMENTS: } \\
\hline \multicolumn{8}{|l|}{ Additional thoracic } \\
\hline \multicolumn{8}{|l|}{$\begin{array}{l}\text { Major thoracic } \\
\text { complications }\end{array}$} \\
\hline Length of stay & & & - & & • & & \\
\hline Mortality & & & & & $x$ & & \\
\hline
\end{tabular}

Figure 1 SPIRIT diagram describing schedule of enrolment, interventions and assessments. SPIRIT, Standard Protocol Items: Recommendations for Interventional Trials.

presenting with HTXs secondary to blunt thoracic trauma that are moderate to large in size will be randomised in a 1:1 ratio to chest drainage or expectant management. We hypothesise non-inferiority of expectant management as compared with pleural drainage in terms of rate of additional thoracic interventions. This study protocol was constructed in accordance with the Standard Protocol Items: Recommendations for Interventional Trials (SPIRIT) 2013 guidelines. ${ }^{15}$ A SPIRIT diagram detailing the timing of screening, randomisation, allocation and assessment is provided in figure 1 .

\section{Trial design}

HTXs are common among patients with blunt thoracic trauma. They are associated with a range of intrathoracic and extrathoracic injuries with varying severity. The trial described below incorporates this real-world variability and therefore adopts a pragmatic trial design. The explanatory versus pragmatic nature of the trial is summarised visually using the pragmatic explanatory continuum indicator summary (PRECIS-2) wheel (figure 2). ${ }^{16}$

\section{Setting}

The study will take place at the Foothills Medical Centre (FMC), a University of Calgary affiliated tertiary care hospital located in Calgary, Alberta, Canada. The FMC is a Trauma Association of Canada (TAC) accredited level 1 trauma centre that provides trauma care to southern
Alberta, Southwest Saskatchewan and Southwest British Columbia.

\section{Eligibility criteria}

The population will consist of all eligible patients presenting with moderate to large sized HTXs $(\geq 300 \mathrm{cc}$, as estimated on CT) secondary to blunt thoracic trauma. HTX size will be evaluated using a previously validated formula: $\mathrm{V}=\mathrm{d}^{2} \times \mathrm{X} \times \mathrm{L}$, where $\mathrm{V}$ is volume of blood in cubic centimetres (cc), d is the greatest depth of HTX from the chest wall to lung on any CT image in centimetres, $\mathrm{X}$ is the thickness of CT slice in centimetres and L is the total craniocaudal length occupied by pleural fluid in centimetres. ${ }^{517}$ HTX size will be calculated by both a trauma team leader and an attending radiologist. The inclusion and exclusion criteria are designed to identify a population of patients presenting with blunt traumatic HTXs who do not have an urgent clinical indication for TT. These are summarised in table 1 .

\section{Consent}

Eligibility will be determined by the attending trauma surgeon at the time of initial admission investigations. Informed consent and randomisation will also occur as soon as possible within a 24-hour window from admission (figure 1). This 24-hour window will begin at the time of admission to our institution in an effort to include eligible patients transferred from other regional centres. 


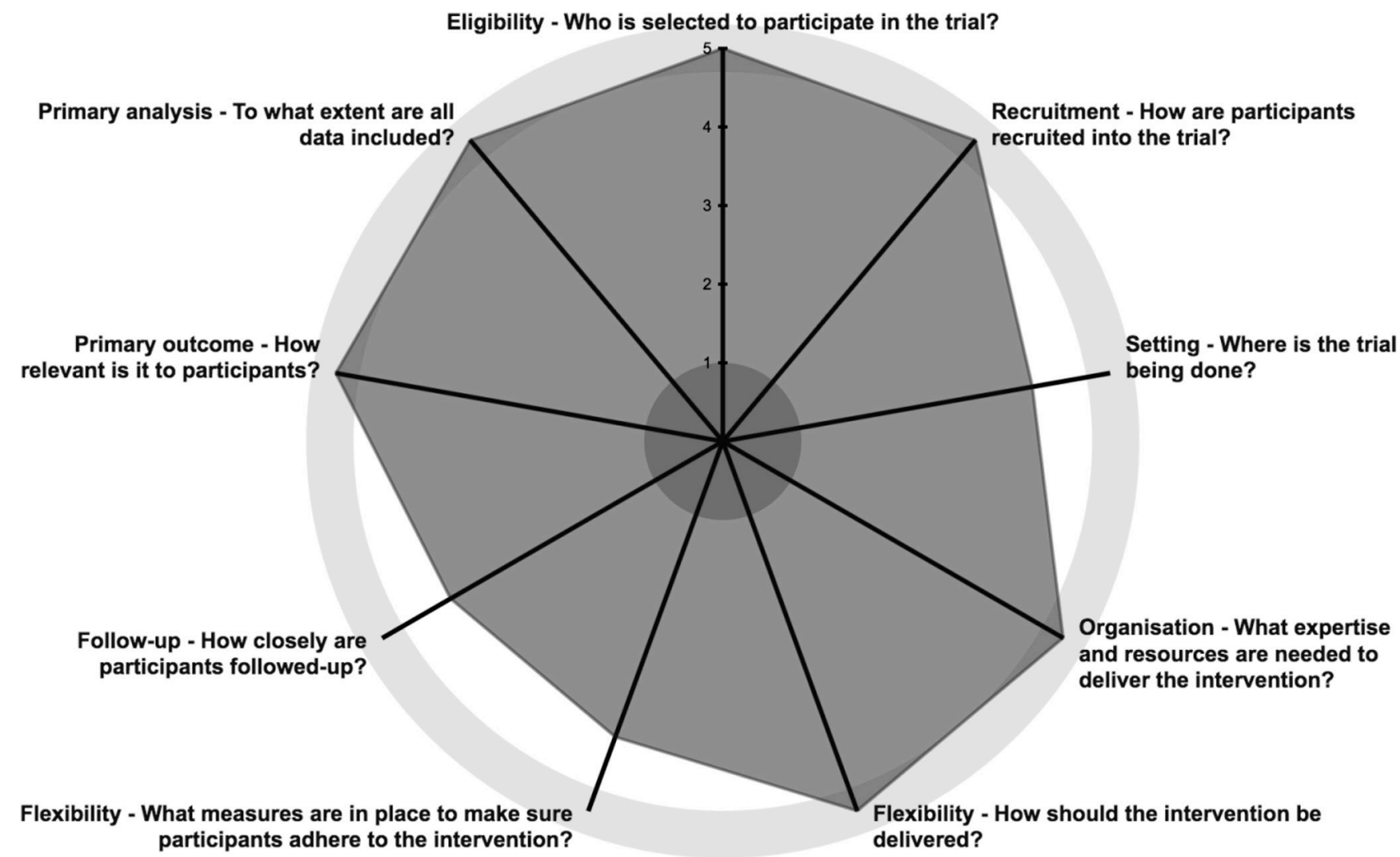

Figure 2 Description of trial design using pragmatic explanatory continuum indicator summary wheel.

The intervention will be applied immediately following randomisation.

\section{Randomisation}

Once eligibility has been determined, participants will be randomised using a block randomisation model (block size 4). The randomisation tool is located on a password-protected website. If an eligible patient has bilateral blunt traumatic haemothoraces, randomisation will occur

\begin{tabular}{|c|c|}
\hline Inclusion criteria & Exclusion criteria \\
\hline Age $\geq 18$ years & $\begin{array}{l}\text { Haemodynamic instability } \\
\text { attributed to } \mathrm{HTX}^{*}\end{array}$ \\
\hline Blunt thoracic injury & $\begin{array}{l}\text { Respiratory distress attributed } \\
\text { to } \mathrm{HTX}^{\star}\end{array}$ \\
\hline \multirow{5}{*}{$\begin{array}{l}\text { Moderate or large } \\
\text { HTX }(\geq 300 \mathrm{cc}) \text { detected on } \\
\text { CT }\end{array}$} & $\begin{array}{l}\text { Any scenario requiring urgent } \\
\text { TT placement }{ }^{\star}\end{array}$ \\
\hline & Penetrating thoracic injury \\
\hline & $\begin{array}{l}\text { Chest tube already in situ (eg, } \\
\text { prior to transfer) }\end{array}$ \\
\hline & $>24$ hours after admission \\
\hline & $\begin{array}{l}\text { Ipsilateral flail chest fracture } \\
\text { pattern }\end{array}$ \\
\hline
\end{tabular}

*In the judgement of the attending trauma surgeon. HTX, haemothorax; TT, tube thoracostomy. for only one side. The intervention will then be applied to both sides.

\section{Interventions}

1. Chest drainage: this group will have an intrapleural catheter placed with the intent of draining all intrapleural blood (HTX). The size and nature of the catheter, manner of placement and timing of removal will be at the discretion of the attending trauma team leader.

2. Observation (expectant management): this group will not have an intrapleural catheter placed on the basis of the HTX, but will undergo standard observation/conservative management by the trauma service. Intrapleural catheters may be placed after enrolment at the attending clinician's discretion. After enrolment, this decision will constitute an outcome variable and require full documentation as to the indications and rationale.

The size and nature of the tube or catheter used for chest drainage will be at the discretion of the attending trauma team leader. Current evidence indicates that the size and nature of the catheter does not impact outcomes in appropriately selected patients. ${ }^{18} 19$ Following chest tube insertion, a standardised protocol will be followed including daily chest X-rays, monitoring of chest tube output and observation for air leak. Again, chest tube removal will be at the discretion of the attending trauma surgeon. 
Table 2 Sample data collection

\begin{tabular}{lll}
\hline Demographics & Injury severity & Admission physiology \\
\hline Age & Mechanism of injury & $\begin{array}{l}\text { Heart and respiratory rate } \\
\text { Gender }\end{array}$ \\
Injury Severity Score & $\begin{array}{l}\text { Blood pressure and mean arterial } \\
\text { pressure }\end{array}$ \\
\hline Comorbid medical conditions & Abbreviated Injury Score & $\mathrm{FiO}_{2} / \mathrm{PaO}_{2}$ ratio \\
\hline Resuscitation requirements & Glasgow Coma Score & Arterial blood gases \\
\hline PRBC, FFP and platelet transfusion & Diagnosis and management of HTX & Complications \\
\hline Crystalloid administration & Presence of HTX on chest X-ray & Retained HTX \\
\hline Factor VIIA administration & Volume estimate of HTX on CT & Empyema \\
\hline Tranexamic acid administration & Presence of pneumothorax & Prolonged air leak \\
Vasopressor administration & Presence of flail chest & Subcutaneous haematoma \\
\hline
\end{tabular}

$\mathrm{FiO}_{2}$, fractional inspired oxygen; FFP, fresh frozen plasma; $\mathrm{HTX}$, haemothorax; $\mathrm{PaO}_{2}$, arterial oxygen pressure; PRBC, packed red blood cell; TT, tube thoracostomy.

Participants allocated to observation can undergo chest drainage or other interventions at the discretion of the attending trauma surgeon if the clinical condition necessitates a change in management. Chest drainage will depend on clinical features such as worsening pain, increasing oxygen requirements, increasing size or haemodynamic consequences. All participants will receive the institutional/trauma service standard of care for all other treatments other than chest tube placement. This includes methods of pain control, venous thromboembolism prophylaxis, and specialist consultation and management of additional injuries.

\section{Data collection}

Data will be collected from both electronic and paperbased medical records by study staff on standardised report forms. Details regarding chest tube size, method of insertion and duration will be recorded for all patients undergoing chest drainage, either following initial randomisation or for those requiring chest drainage following randomisation to observation. A sample of additional recorded data points is included in table 2. After hospital discharge, participants will be assessed for progress and potential complications in a dedicated outpatient trauma clinic approximately 30 and 90 days after randomisation. This outpatient follow-up will include chest X-rays to monitor for radiological resolution. The attendance of blunt injured patients within our trauma clinic has traditionally been very high $(>90 \%)$. All study documents will be maintained in a secure location in a locked office.

\section{Outcomes}

Outcomes will be assessed by the attending trauma surgeon, trauma fellow and other study authors. Assessments will include daily physical examinations, blood tests and chest X-ray. Primary outcomes include the rate of additional thoracic interventions (ie, additional TT insertion, image-guided drainage, video-assisted thoracic surgery or thoracotomy). Secondary outcomes include the rate of empyema, tracheostomy, inhospital mortality, intensive care unit, length of stay (LOS), overall hospital LOS and days of mechanical ventilation.

\section{Sample size}

The reported rate of retained HTX after TT is approximately $33 \% .^{6}$ Using this as a surrogate for failure of the intervention, the rate of success of TT is estimated as $67 \%$. Sample size was then calculated assuming (1) non-inferiority of the expectant management group; (2) significance level (alpha) of 0.05 ; (3) power (beta) of $90 \%$ and (4) an expected difference in event rates of $15 \%$. One hundred and sixty-nine patients will be randomised to each intervention.

\section{Analysis}

An intention-to-treat analysis will be used. Descriptive statistics will be used to describe the patients in both treatment arms. Continuous variables will be compared using Student's t-test and the Mann-Whitney U test. The $\chi^{2}$ test or Fisher's exact test will be used to compare categorical variables. Multivariate analysis will be done to compare mortality rates of the different management received but also to account for other potential confounding variables. All variables with a $\mathrm{P}$ value $<0.2$ on univariate analysis will be entered into a multivariable logistic regression analysis to identify independent risk factors for mortality and morbidity. Statistical analysis will be performed with STATA.

\section{CONCLUSION}

The management of haemothoraces in blunt trauma remains an area of clinical equipoise. This trial aims to compare chest drainage and expectant management in blunt traumatic haemothoraces. This will further clarify the role of expectant management that has been 
described in previous observational reports. ${ }^{8-12}$ Blunt traumatic haemothorax is a very common condition and the results of this study have the potential to improve the quality of care for trauma patients around the world.

Contributors CGB is the principal investigator and has coordinated all phases of trial design, statistical analysis plan and drafting of the protocol. AKB, CS, SCG, AWK, RL, PBM and MBD contributed to the development of the trial design. DAC and $A K B$ critically appraised the trial design, participated in study coordination and wrote the manuscript. All authors contributed to the writing of the manuscript and agreed with submission of the final version for publication.

Funding This research received no specific grant from any funding agency in the public, commercial or not-for-profit sectors.

Competing interests None declared.

Patient consent Detail has been removed from this case description/these case descriptions to ensure anonymity. The editors and reviewers have seen the detailed information available and are satisfied that the information backs up the case the authors are making.

Ethics approval Conjoint Health Research Ethics Board at the University of Calgary (REB16-1056).

Provenance and peer review Not commissioned; externally peer reviewed.

Open Access This is an Open Access article distributed in accordance with the Creative Commons Attribution Non Commercial (CC BY-NC 4.0) license, which permits others to distribute, remix, adapt, build upon this work non-commercially, and license their derivative works on different terms, provided the original work is properly cited and the use is non-commercial. See: http://creativecommons.org/ licenses/by-nc/4.0/

(C) Article author(s) (or their employer(s) unless otherwise stated in the text of the article) 2018. All rights reserved. No commercial use is permitted unless otherwise expressly granted.

\section{REFERENCES}

1. Manlulu AV, Lee TW, Thung KH, et al. Current indications and results of VATS in the evaluation and management of hemodynamically stable thoracic injuries. Eur J Cardiothorac Surg 2004;25:1048-53.
2. Ball CG, Lord J, Laupland KB, et al. Chest tube complications: how well are we training our residents? Can J Surg 2007;50:450-8.

3. DuBose J, Inaba K, Okoye O, et al. Development of posttraumatic empyema in patients with retained hemothorax: results of a prospective, observational AAST study. J Trauma Acute Care Surg 2012;73:752-7.

4. Bradley M, Okoye O, DuBose J, et al. Risk factors for posttraumatic pneumonia in patients with retained haemothorax: results of a prospective, observational AAST study. Injury 2013:44:1159-64

5. DuBose J, Inaba K, Demetriades D, et al. Management of posttraumatic retained hemothorax: a prospective, observational, multicenter AAST study. J Trauma Acute Care Surg 2012;72:11-24.

6. Stafford RE, Linn J, Washington L. Incidence and management of occult hemothoraces. Am J Surg 2006;192:722-6.

7. Mowery NT, Gunter OL, Collier BR, et al. Practice management guidelines for management of hemothorax and occult pneumothorax. J Trauma 2011;70:510-8.

8. Khandhar SJ, Johnson SB, Calhoon JH. Overview of thoracic trauma in the United States. Thorac Surg Clin 2007;17:1-9.

9. Kulshrestha P, Munshi I, Wait R. Profile of chest trauma in a level I trauma center. J Trauma 2004;57:576-81.

10. Liman S, et al. Chest injury due to blunt trauma. Eur J Cardiothorac 2003;23:374-8.

11. Bilello JF, Davis JW, Lemaster DM. Occult traumatic hemothorax: when can sleeping dogs lie? Am J Surg 2005;190:844-8.

12. Wells BJ, Roberts DJ, Grondin S, et al. To drain or not to drain? Predictors of tube thoracostomy insertion and outcomes associated with drainage of traumatic hemothoraces. Injury 2015;46:1743-8.

13. Stein A, Schnier G. Penetrating stab wounds of the chest. $S$ Afr Med $J$ 1965;39:548-53

14. Shnier G, Stein A. Stab wounds of the chest. J Med Radiol Australas 1964;8:48-54.

15. Chan AW, Tetzlaff JM, Altman DG, et al. SPIRIT 2013: new guidance for content of clinical trial protocols. Lancet 2013;381:91-2.

16. Loudon K, Treweek S, Sullivan F, et al. The PRECIS-2 tool: designing trials that are fit for purpose. BMJ 2015;350:h2147.

17. Mergo PJ, Helmberger T, Didovic J, et al. New formula for quantification of pleural effusions from computed tomography. $J$ Thorac Imaging 1999;14:122-5.

18. Inaba K, Lustenberger T, Recinos G, et al. Does size matter? A prospective analysis of 28-32 versus 36-40 French chest tube size in trauma. J Trauma Acute Care Surg 2012;72:422-7.

19. Kulvatunyou N, Joseph B, Friese RS, et al. 14 French pigtail catheters placed by surgeons to drain blood on trauma patients: is 14-Fr too small? J Trauma Acute Care Surg 2012;73:1423-7. 